\title{
Optimizing Management of the Measurement System of the Technological Process
}

\section{Dana Jenčuráková, Rudolf Palenčár}

Institute of automation, measurement and applied informatics, Faculty of Mechanical Engineering, Slovak University of Technology in Bratislava, Námestie Slobody 17, 81231 Bratislava, Slovak Republic, E-mail: dana.jencurakova@gmail.com,rudolf.palencar@stuba.sk

The present contribution represents the analysis and optimizing management of the measurement system of the technological process of pressing. It has been chosen the combination of appropriate methods for achieving the objective to minimize the cost of quality assurance of the measurement process by means its management. The quality of the measurement process has been verified by the reference standard (etalon). The optimization of evaluation measurement has been searched by utilizing QFD method (Quality Function Deployment). The subsequent optimization has been implemented by the taking into account the results of the use of the control charts and the deployment of QFD method and Kalman filter.

Keywords: Measurement System, Control Chart, QFD Method, Kalman Filter, Management, Quality, Optimization

\section{Acknowledgement}

The paper was supported by the Faculty of Mechanical Engineering of Slovak University of Technology in Bratislava, grant from Grant Agency VEGA, project No. 1/0604/15 and No. 1/0748/15 and grant from Grant Agency KEGA, project No. 014STU-4/2015.

\section{References}

[1] DUCAN, A. J. (1974). Quality Control and Industrial Statistics. Irwin, Homewood.

[2] MONTGOMERY, D. C. (1991). Introduction to Statistical Quality Control. John Wiley, New York.

[3] FRANCESCHINI, F. (2001). Advanced Quality Function Deployment. CRP Press, New York.

[4] FICALORA, J. P., COHEN, L. (2009). Quality Function Deployment and Six Sigma. Prentice Hall, New York.

[5] ISO 3534-2:2006. Statistics -- Vocabulary and symbols -- Part 2: Applied statistics.

[6] JCGM 100:2008. GUM 1995 with minor corrections. Evaluation of measurement data - Guide to the expression of uncertainty in measurement.

[7] SIMON, D. (2006). Optimal State Estimation: Kalman, H Infinity and Nonlinear Approaches. Wiley, New York.

[8] WILLSKY, A. S. (1976). A Survey of Design Methods for Failure Detection in Dynamic Systems. In: Automatica, Vol. 12, pp. 601-611. Pergamon Press, Oxford.

[9] JAZWINSKI, A. H. (1969). Adaptive filtering. In: Automatica, Vol. 5, No. 4, pp. 475-485. [Online]. Available: http://dx.doi.org/10.1016/0005-1098(69)90109-5. 